Article

\title{
Synthesis, Characterization and Catalytic Polymerization of $N$-Methyl Imidazolium Phosphotungstic Catalyst
}

\section{Dianyu Chen *, Zhaoyi Deng, Xiaoqin Liu and Rong Wang}

Jiangsu Key Laboratory of Advanced Functional Materials, Department of Chemistry and Materials Engineering, Changshu Institute of Technology, Changshu 215500, China;

E-Mails: d1170351808@163.com (Z.D.); 1xq2124@163.com (X.L.); wr2833@sina.com (R.W.)

* Author to whom correspondence should be addressed; E-Mail: chendy@cslg.edu.cn; Tel.: +86-512-5225-1842.

Academic Editor: Keith Hohn

Received: 6 September 2015 / Accepted: 3 November 2015 / Published: 9 November 2015

\begin{abstract}
N$-methyl imidazolium phosphotungstic salt has been synthesized and used as a special catalyst for photopolymerization of vinyl monomers. This is a fast and smooth reaction, and high molecular weight polymers with narrow polydispersity are obtained within $60 \mathrm{~min}$. The compound was structurally characterized by elemental analysis, IR spectroscopy, and ${ }^{1} \mathrm{H}$ NMR spectroscopy. The electrochemical property is determined on a CHI 660 electrochemistry workstation. The polymerization initiated by $N$-methyl imidazolium phosphotungstic salt showed controlling characteristics, the catalyst can be easily isolated from polymer product, and reused for at least 10 times.
\end{abstract}

Keywords: $N$-methyl imidazolium phosphotungstic salt; electrochemical; catalytic polymerization; recoverable

\section{Introduction}

Heteropoly acids (HPAs) have attracted significant attention because of their high acidity and favorable redox properties [1-8]. Among different HPAs, Keggin type (such as phosphotungstic acid) are well known and widely studied compounds for various catalytic applications, such as Friedel-Craft's alky-lation, acylation, oxidation, hydration of alkenes, esterification, transesterification, and carbonylation [9-14]. 
Heteropoly acids (HPAs) and compounds were firstly employed in our research group to initiate styrene for polymerization $[15,16]$, which was the only polymerization example for vinyl monomers.

Styrene polymerization initiated by HPA was excellent, and followed cationic polymerization theory [15]. However, the reaction carried out so rapidly that it disadvantaged both experimental research and plant application. This limited the use of a wide range of vinyl monomers in polymerization. As such it requires a suitable method to address the problem of HPA-mediated cationic polymerization. One of the best methods was selecting a suitable ligand to stabilize the active center during polymerization.

In present paper, $N$-methyl imidazolium was used for modifying the stability of phosphotungstic acid (PTA). The compound was structurally characterized by elemental analysis, IR spectroscopy, and ${ }^{1} \mathrm{H}$ NMR spectroscopy. The electrochemical property was determined on a CHI 660 electrochemistry workstation. The catalysis activity was studied in photopolymerization of vinyl monomers.

\section{Results and Discussion}

\subsection{IR Analysis}

Figure 1 shows the FT-IR spectra of the as-prepared catalysts: $\mathrm{H}_{3} \mathrm{PW}_{12} \mathrm{O}_{40}(\mathrm{a}) ;\left[\left(\mathrm{C}_{3} \mathrm{H}_{3}\right) \mathrm{N}_{2} \mathrm{CH}_{3}\right]_{3}$ $\left(\mathrm{PW}_{12} \mathrm{O}_{40}\right)(\mathrm{b})$; the catalyst after one cycle of polymerization (c); and the catalyst after 10 cycles of polymerization (d). Over a range of $800-1100 \mathrm{~cm}^{-1}$, the absorption bands around 1080, 985, 896, and $804 \mathrm{~cm}^{-1}$, corresponding to the four characteristic skeletal vibrations of the Keggin oxoanions, were observed in the FT-IR spectra of sample (a). These absorption bands are attributed to the vibrations of vas $\left(\mathrm{P}-\mathrm{O}_{\mathrm{a}}\right)$, $\operatorname{vas}\left(\mathrm{W}=\mathrm{O}_{\mathrm{d}}\right)$, and $\operatorname{vas}\left(\mathrm{W}-\mathrm{O}_{\mathrm{b}}-\mathrm{W}\right)$ in corner-shared octahedra, and vas $\left(\mathrm{W}-\mathrm{O}_{\mathrm{c}}-\mathrm{W}\right)$ in edge-shared octahedra, respectively [17-19]. For the FT-IR spectrum of the samples from (b) to (d), the absorption band at $1080 \mathrm{~cm}^{-1}$ is attributed to the vibration of vas $\left(\mathrm{P}-\mathrm{O}_{\mathrm{a}}\right)$, the absorption bands of vas $\left(\mathrm{W}=\mathrm{O}_{\mathrm{d}}\right)$, vas( $\left.\mathrm{W}-\mathrm{O}_{\mathrm{b}}-\mathrm{W}\right)$, and vas( $\mathrm{W}-\mathrm{O}_{\mathrm{c}}-\mathrm{W}$ ) shift to 984 (for b, 982 for $\mathrm{c}$, and 982 for $\mathrm{d}$ ), 894 (for b, 898 for $\mathrm{c}$, and 896 for d), and 811 (for b, 820 for c, and 808 for d) $\mathrm{cm}^{-1}$. These shifts indicate the changes of the bond length and bond angle. Compared with the spectra of sample (a), high similarity was found in these bands of samples (b) to (d), which indicated that the Keggin structure was not destroyed after modified by $N$-methyl imidazolium and, secondly, no change was found during the catalysis polymerization. The possible reason of these band changes is that the $\mathrm{MoO}_{6}$ octahedra of the polyanions were distorted in some degrees because of the influence of the $N$-methyl imidazolium cations. 

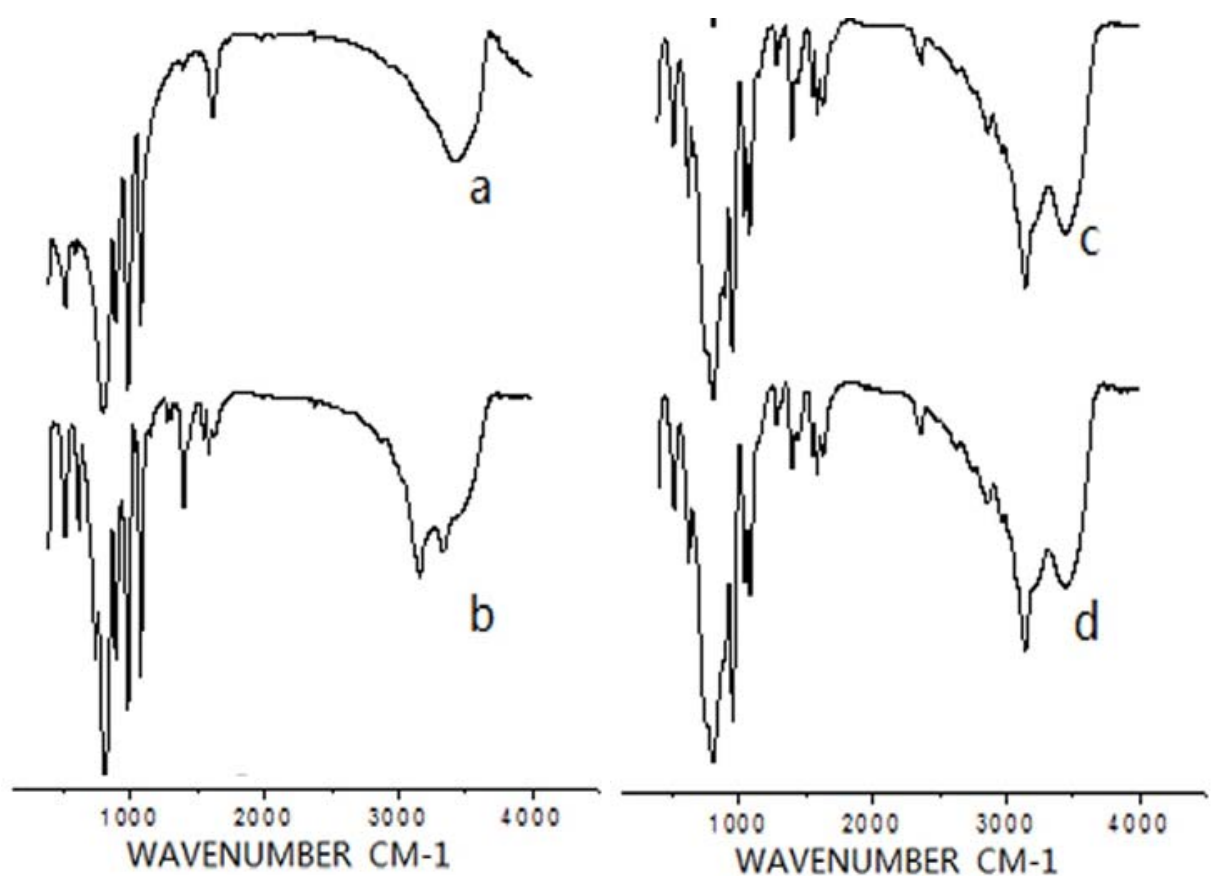

Figure 1. IR analysis. (a) phosphotungstic acid; (b) $N$-methyl imidazolium phosphotungstic salt; (c) the catalyst after one cycle of polymerization; and (d), the catalyst after 10 cycles of polymerization.

\section{2. ${ }^{1} H$ NMR Analysis}

From Figure 2a, the peak at $5.416 \mathrm{ppm}$ was attributed to the protons in phosphotungstic acid, and the peak at $2.475 \mathrm{ppm}$ was attributed to the solvent of $\mathrm{CD}_{3} \mathrm{COCD}_{3}$. That is, all of the protons in phosphotungstic acid were in the same chemical environments. Figure $2 b$ shows the ${ }^{1} \mathrm{H}$ NMR spectrum of $N$-methyl imidazolium phosphotungstic salt, the peak at $5.416 \mathrm{ppm}$ disappeared, and four new peaks appeared: $8.83 \mathrm{ppm}$ was attributed to $\mathrm{C}^{2} \mathrm{H}, 7.61 \mathrm{ppm}$ and $7.55 \mathrm{ppm}$ were attributed to $\mathrm{C}^{4} \mathrm{H}$ and $\mathrm{C}^{5} \mathrm{H}$, and 3.78 ppm was attributed to $\mathrm{C}^{6} \mathrm{H}_{3}$ (see the formula in Figure 2), which might indicate that the protons in phosphotungstic acid had transferred from phosphotungstic acid to the $\mathrm{N}$ atom of $\mathrm{N}$-methyl imidazolium unit. The possible reaction process was deduced as follows:<smiles>Cn1cc[nH+]c1</smiles>

After catalytic polymerization (Figure 2c,d), the four peaks in Figure $2 \mathrm{~b}$ were shifted to 8.63, 7.53, 7.43, and $3.82 \mathrm{ppm}(8.60,7.52,7.42$ and 3.81 in Figure 2c,d) separately. The same result as the IR analysis was obtained; that is, $N$-methyl imidazolium phosphotungstic salt had a stable structure, and could be reused several times. 


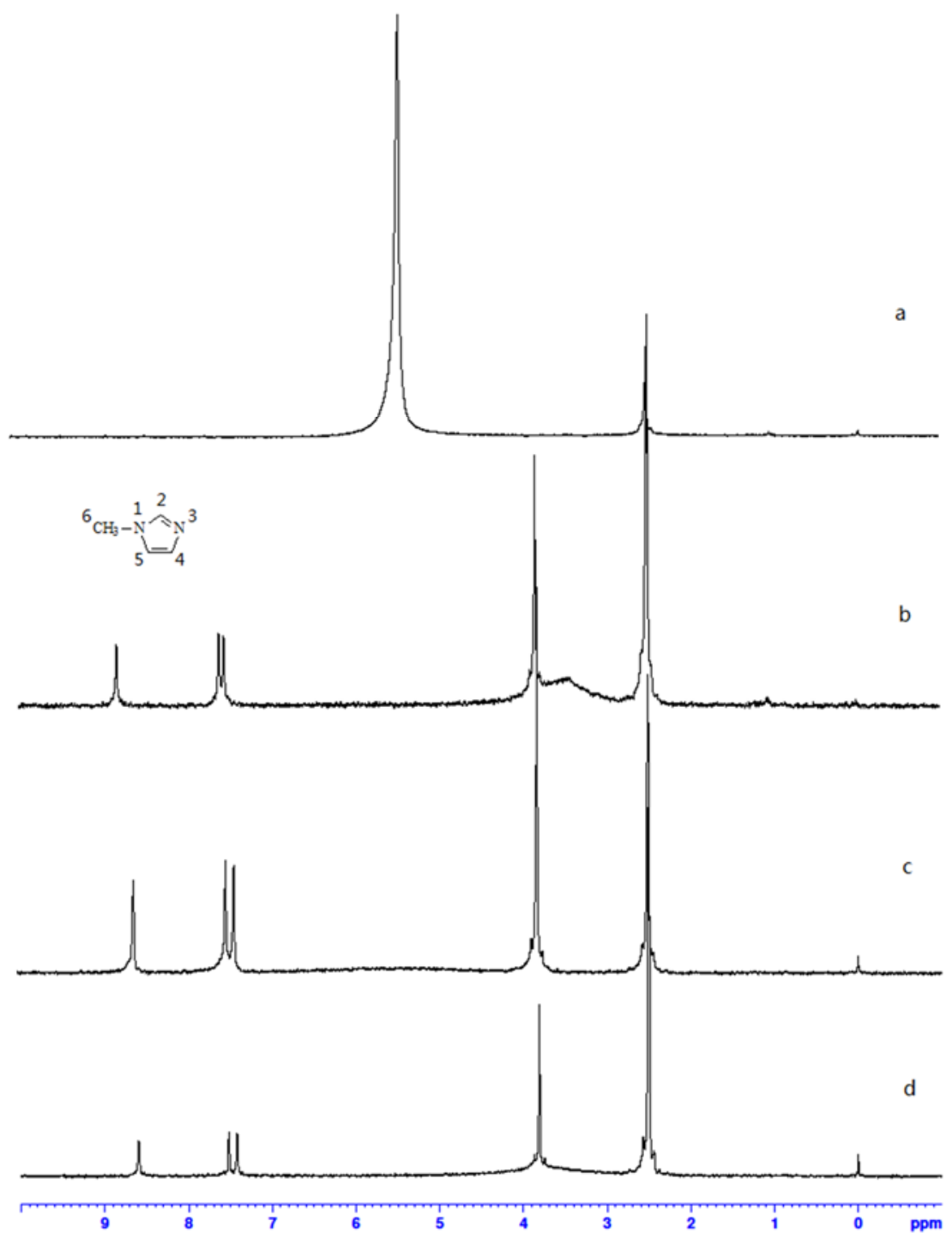

Figure 2. ${ }^{1} \mathrm{H}$ NMR spectra. (a) phosphotungstic acid; (b) $N$-methyl imidazolium phosphotungstic salt; (c) the catalyst after one cycle of polymerization; (d) the catalyst after 10 cycles of polymerization.

\subsection{Electro-Chemical Property Analysis}

Figure 3 showed cyclic voltammograms (CVs) of the aimed product in $0.5 \mathrm{M}$ buffer solution of HAc-NaAc with a different scan rate. Redox potential was shown at 1.08 and 0.57 when the scan rate was selected as $100 \mathrm{mV} / \mathrm{s}$. With an increase of the scan rate, the oxidation peak potential shifted more positively and the reduction potential shifted more negatively, while the peak currents increased linearly with an increase of the square of the scan rate (inset A). This revealed that the electrochemical behavior of the complex chemsorbed on the surface of the ligands showing a diffusion-confined redox process [20].

Additionally, the electrode modified by the complex had high stability. In $0.5 \mathrm{M}$ buffer solution of HAc-NaAc and potential range of $-0.4-1.6 \mathrm{~V}$, the peak currents had no weakening after scanning 300 times, and even laying aside for two months. This indicated the potential application in both the chemical sensor and recovery catalyst. 


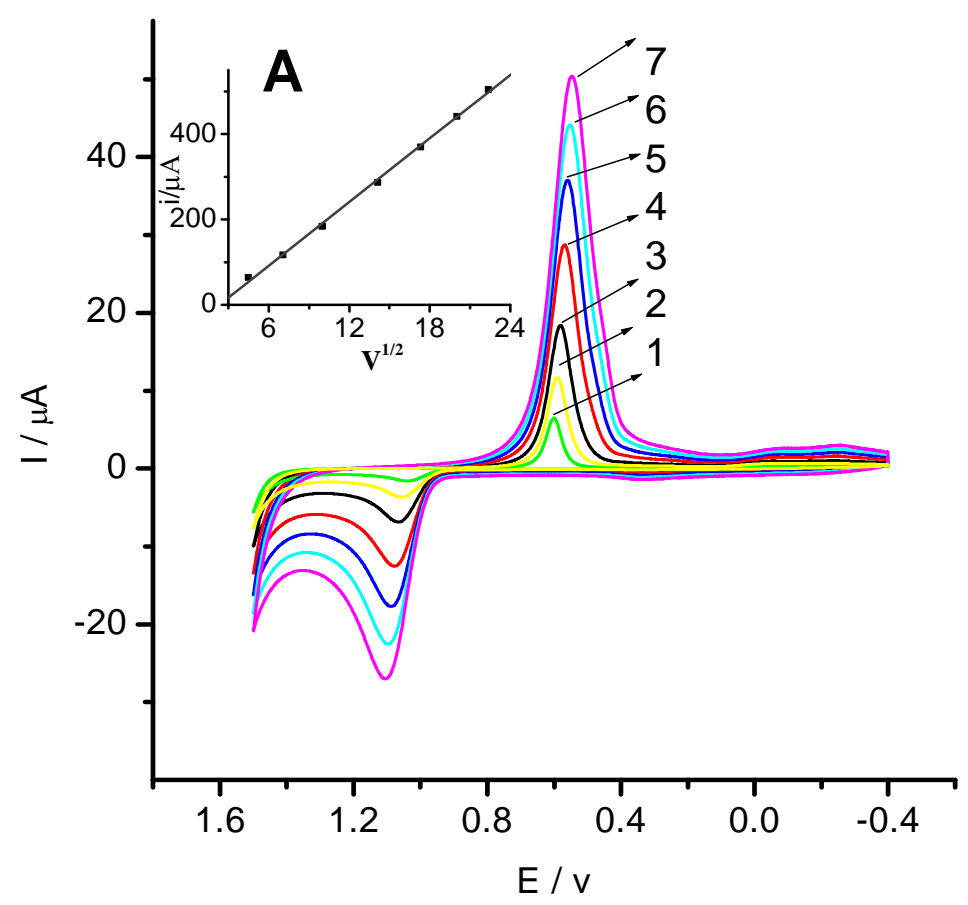

Figure 3. Cyclic voltammograms of gold/complex electrode (solid line) in a $0.5 \mathrm{M}$ buffer solution of HAc-NaAc. 1-7: 20, 50, 100, 200, 300, 400, and $500 \mathrm{mV} \cdot \mathrm{s}^{-1}$ (from inside to outside). Inset (A): the variation of cathodic peak current with scan rate.

\subsection{Catalytic Activity}

Polymerizations of styrene with this catalyst proceed readily under a $359 \mathrm{~nm}$ light radiation for $60 \mathrm{~min}$ at room temperature. This is a fast and smooth reaction when compared to the polymerization initiated by phosphotungstic acid [15]. The increase in rate is manifested by a lowering of molecular weight from 5464 to 1304 , and broadening of the polydispersity from 1.21 to 3.11 , which is ascribed to the chain transfer reaction [21]. These observations led us to lower the reaction temperature and radiation power, in an attempt to avoid an excessive chain transfer reaction. Polymerization proceeds efficiently at Reaction 3, reaching $73 \%$ conversion after $60 \mathrm{~min}$ at $20^{\circ} \mathrm{C}$ and $300 \mathrm{~W}$ power. When the molar ratio of monomer to catalyst was doubled from 50 to 100, an approximate doubling of the $\mathrm{Mn}$ is observed (Reactions 3 and 9, Table 1), as would be expected for a controlling polymerization.

Styrene, vinyl acetate, methyl methacrylate, and butyl acrylate were used, as representative of the vinyl monomers, for the photopolymerization initiated by $N$-methyl imidazolium phosphotungstic salt (Reactions 3, 10, 11, and 12, Table 1). All reactions at $20^{\circ} \mathrm{C}$ and $300 \mathrm{~W}$ showed very good catalytic activity. This, taken together with the relatively narrow PDI values and high $\mathrm{Mn}$ of the products, indicated that the polymerization shows controlled characteristics. Figure 4 showed the evolution of $\mathrm{Mn}$ as a function of $[\mathrm{M}] /[\mathrm{Cat}]$ for Reaction $3,10,11$, and 12, which increased linearly, again as would be expected for controlling polymerization. 
Table 1. Final molecular weight and conversion data for the polymers synthesized in this work.

\begin{tabular}{|c|c|c|c|c|c|c|}
\hline Reaction $^{\text {a }}$ & Temperature $/{ }^{\circ} \mathrm{C}$ & Time/min & Power/W & Conversion $/ \%^{b}$ & $\mathbf{M n}^{\mathrm{c}}$ & PDI $^{c}$ \\
\hline $1^{d}$ & 20 & 40 & 300 & 63 & 4531 & 1.26 \\
\hline $2^{d}$ & 20 & 50 & 300 & 70 & 4917 & 1.23 \\
\hline $3^{d}$ & 20 & 60 & 300 & 72 & 5464 & 1.21 \\
\hline $4^{d}$ & 30 & 60 & 300 & 65 & 5006 & 1.62 \\
\hline $5^{d}$ & 40 & 60 & 300 & 43 & 3564 & 1.67 \\
\hline $6^{d}$ & 50 & 60 & 300 & 16 & 2833 & 2.16 \\
\hline $7^{d}$ & 20 & 60 & 500 & 65 & 4654 & 2.23 \\
\hline $8^{d}$ & 20 & 60 & 800 & 58 & 1303 & 3.11 \\
\hline $9^{\mathrm{d}, *}$ & 20 & 120 & 300 & 58 & 11437 & 1.31 \\
\hline $10^{\mathrm{e}}$ & 20 & 60 & 300 & 75 & 7407 & 1.27 \\
\hline $11^{\mathrm{f}}$ & 20 & 60 & 300 & 59 & 7689 & 1.21 \\
\hline $12^{\mathrm{g}}$ & 20 & 60 & 300 & 68 & 8230 & 1.54 \\
\hline
\end{tabular}

${ }^{\mathrm{a}}$ All reactions carried were $50 \% \mathrm{v} / \mathrm{v}$ in acetone. ${ }^{\mathrm{b}}$ Conversion from integration of ${ }^{1} \mathrm{HNMR} .{ }^{\mathrm{c}}$ Determined using PL GPC-50 against polystyrene standards. Vinyl monomer: ${ }^{\mathrm{d}}$ styrene; ${ }^{\mathrm{e}}$ vinyl acetate; ${ }^{\mathrm{f}}$ methyl methacrylate; ${ }^{\mathrm{g}}$ butyl carylate. [monomer]/[catalyst]: ${ }^{\mathrm{d}} 50: 1 ;{ }^{\mathrm{d}} * * 100: 1$.

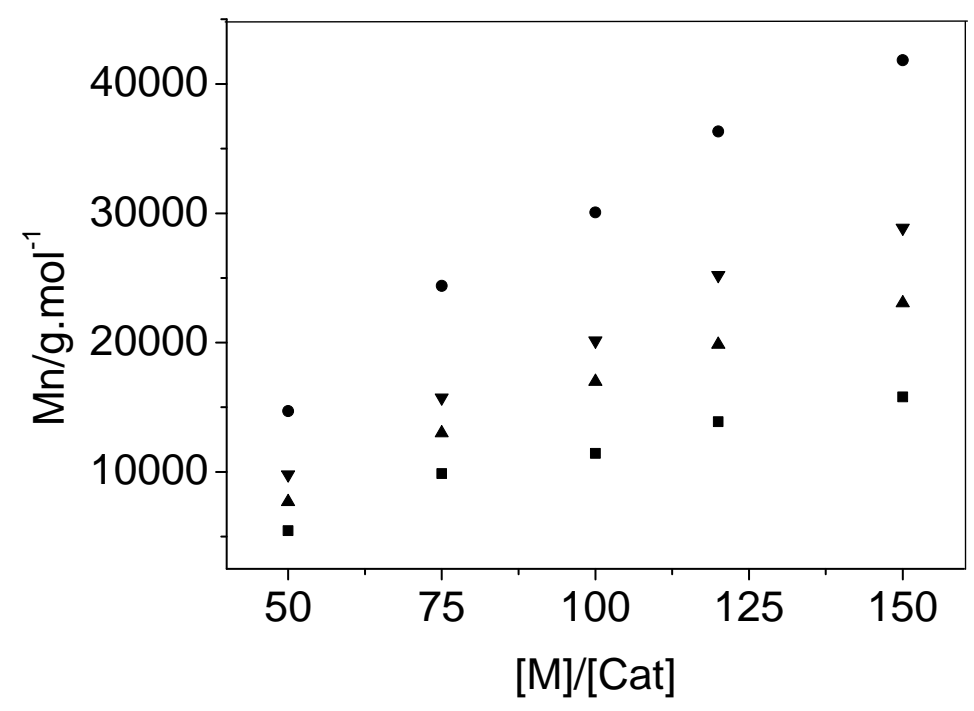

Figure 4. Evolution of molar mass with $[\mathrm{M}] /[\mathrm{Cat}]$ for polymerization; (a) polystyrene, (•) poly(vinyl acetate), ( $\boldsymbol{\Delta})$ poly(methyl methacrylate), and ( $\boldsymbol{\nabla})$ poly(butyl acrylate).

$N$-methyl imidazolium phosphotungstic salt is insoluble with most of organic solvents, such as acetone, toluene, and so on, which allows easy isolation of the catalyst from the polymerization system for potential reuse. After 10 cycles of reuse in styrene polymerization (see Figure 5), catalyst recovery is up to $92.4 \%$, molecular weight and polydispersity of polystyrene retained a stable level (Mn changed randomly between 8194 and 10695, PDI changed randomly between 1.15 and 1.67), which indicated that $N$-methyl imidazolium phosphotungstic salt was a recovery catalyst, and could be used repeatedly 10 times, at least. 


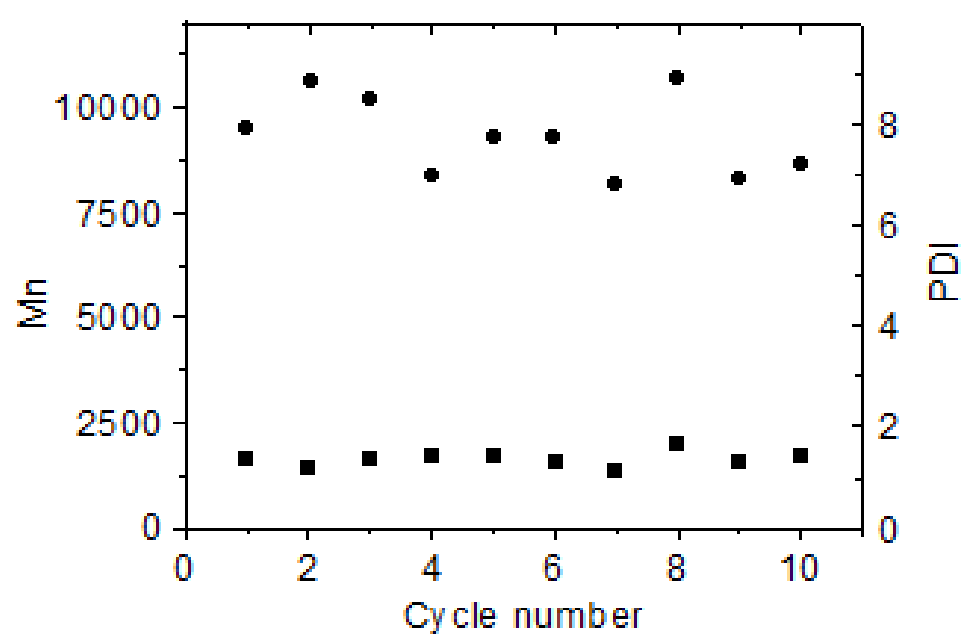

Figure 5. The recovery results of the catalyst. $\bullet, \mathrm{Mn} ; \mathbf{\square}$, PDI.

\section{Experimental Section}

\subsection{Materials and Instruments}

All chemicals purchased were of reagent grade and used without further purification. The elemental analyses for $\mathrm{C}, \mathrm{H}$, and $\mathrm{N}$ were performed with an EA1110-CHNS elemental analyzer (CARLO-ERBA, ERBA, Italy). The IR spectra were obtained on a NICOLET380 spectrum (THERMO, Waltham, MA, USA) using $\mathrm{KBr}$ disks in the range $4000-400 \mathrm{~cm}^{-1}$. ${ }^{1} \mathrm{H}$ NMR spectra were recorded on a BRUKER Avance DPX 300MHz spectrometer (BRUKER, Tucson, AZ, USA). Polymerization was performed in a XPA-1 photochemical reactor (Xujiang, Nanjing, China), with a $300 \mathrm{~W} \mathrm{Hg}$ light source, and the rolling rate was $20 \mathrm{rpm}$, the wavelength of the radiation light was selected as $365 \mathrm{~nm}$. Molecular weight and molecular weight distribution of the polymers were measured by PL GPC 50 (AGILENT, Cheshire, UK) at $25{ }^{\circ} \mathrm{C}$ using THF as eluent against polystyrene standards, flow rate: $1 \mathrm{~mL} / \mathrm{min}$, sample concentration: $1 \mathrm{mg} / \mathrm{mL}$.

\subsection{Catalyst Preparation}

$\mathrm{H}_{3} \mathrm{PW}_{12} \mathrm{O}_{40} \cdot 16.5 \mathrm{H}_{2} \mathrm{O}$ of $6.35 \mathrm{~g}(0.002 \mathrm{~mol})$ was dissolved in $24 \mathrm{~mL}$ of ethanol and heated at $40{ }^{\circ} \mathrm{C}$ for $30 \mathrm{~min}$ under stirring. Then, $0.49 \mathrm{~g}$ of $\left[\left(\mathrm{C}_{3} \mathrm{H}_{3}\right) \mathrm{N}_{2} \mathrm{CH}_{3}\right](0.006 \mathrm{~mol})$ in ethanol $(58 \mathrm{~mL})$ was added to the solution dropwise under stirring. The solution was stirred continuously for $8 \mathrm{~h}$. The resultant precipitate was filtered and washed with ethanol. After drying in a vacuum oven at $30{ }^{\circ} \mathrm{C}$ for $12 \mathrm{~h}$, a white powder catalyst was obtained. Yield: $77.8 \%$ (based on W). Anal. Calcd for $\mathrm{C}_{12} \mathrm{H}_{18} \mathrm{~N}_{6} \mathrm{O}_{40} \mathrm{PW}_{12}$ : C: 4.59; N: 2.68; H: 0.57\%. Found: C: 4.62; N: 2.61; H: 0.62\%.

\subsection{Electrochemical Property Determination}

All electrochemical measurements were carried out on a CHI 660 electrochemistry workstation (Chenghua, Shanghai, China). A three-electrode setup was employed for the electrochemical studies, gold $(\mathrm{Au})$ was utilized as the working electrode, modified with the complex acetone solution. A platinum disk was used as the counter electrode, and the reference electrode was a saturated calomel reference 
electrode (SCE). Before being used, the oxidized gold working electrode surfaces were generated by applying $2.0 \mathrm{~V}$ vs. SCE for $90 \mathrm{~s}$ in $2 \mathrm{M} \mathrm{NaOH}$ solution.

\subsection{Typical Polymerization Process}

The catalytic activity test of $\mathrm{N}$-methyl imidazolium phosphotungstic salt was performed as follows: $\left[\left(\mathrm{C}_{3} \mathrm{H}_{3}\right) \mathrm{N}_{2} \mathrm{CH}_{3}\right]_{3}\left(\mathrm{PW}_{12} \mathrm{O}_{40}\right)$ of $0.31 \mathrm{~g}(0.1 \mathrm{mmol})$ was mixed with $10 \mathrm{~g}$ of acetone in a quartz reaction tube, stirred by magnetic power. Dry nitrogen was input for about $20 \mathrm{~min}$ to eliminate the effect of possible air, and then $0.10 \mathrm{~g}(10 \mathrm{mmol})$ of styrene was added. The polymerization was performed on a XPA-1 photochemical reactor, with $300 \mathrm{~W} \mathrm{Hg}$ light source and the rolling rate was $20 \mathrm{rpm}$, the wavelength of the radiation light was selected as $365 \mathrm{~nm}$. The polymerization was terminated by addition of acidic methanol, the polymer product was precipitated into $50 \mathrm{~mL}$ methanol, filtered, washed with methanol, and dried in a vacuum oven at $50{ }^{\circ} \mathrm{C}$ overnight to a constant weight. The catalyst was filtered and washed three times with acetone, and then dried in vacuum at $80{ }^{\circ} \mathrm{C}$ for reuse.

Gel permeation chromatography (GPC) analyses of polymer samples were carried out at $25^{\circ} \mathrm{C}$ using THF as eluent on a Polymer Laboratory-50 instrument and calibrated using monodispersed polystyrene standards at a flow rate of $1.0 \mathrm{~mL} / \mathrm{min}$. Number-average molecular weight and polydispersity of polymers were given relative to PS standards.

\section{Conclusions}

In summary, $N$-methyl imidazolium phosphotungstic salt was an excellent catalyst for the polymerization of vinyl monomers. Polymerizations showed controlled characteristics, and the catalyst could be isolated easily and reused for at least 10 times.

\section{Author Contributions}

Dianyu Chen conceived and designed the experiments; Zhaoyi Deng performed the experiments; Zhaoyi Deng and XiaoqinLiu characterized the catalyst; Xiaoqin Liu determined electrochemical property; Rong Wang operated GPC and obtained Mn and PDI of the polymer product.

\section{Conflicts of Interest}

The authors declare no conflicts of interest.

\section{References}

1. Ramesh Kumar, C.; Gatla, S.; Mathon, O.; Pascarelli, S.; Lingaiah, N. The role of niobia location on the acidic and catalytic functionalities of heteropoly tungstate. Appl. Catal. A 2015, 502, 297-304.

2. Yu, F.L.; Liu, C.Y.; Yuan, B.; Xie, C.X.; Yu, S.T. Self-assembly heteropoly acid catalyzed oxidative desulfurization of fuel with oxygen. Catal. Commun. 2015, 68, 49-52.

3. Alessandro, S.; Irene, G.; Ada, S.; Vincenzo, B.; Antonino, S.A. Enhancement of Oxygen Reduction and Mitigation of Ionomer Dry-Out Using Insoluble Heteropoly Acids in Intermediate Temperature Polymer-Electrolyte Membrane Fuel Cells. Energies 2015, 8, 7805-7817. 
4. Wu, X.F.; Wu, W.; Qian, X.Y.; Wu, Q.Y.; Yan, W.F. Proton-conducting materials based on heteropoly acid and matrixes. J. Non-Cryst. Solids 2015, 426, 88-91.

5. Hernández-Cortez, J.G.; Manríquez M.; Lartundo-Rojas, L.; López-Salinas, E. Study of acid-base properties of supported heteropoly acids in the reactions of secondary alcohols dehydration. Catal. Today 2014, 220-222, 32-38.

6. Klein, M.; Pulidindi, I.N.; Perkas, N.; Gedanken, A. Heteropoly acid catalyzed hydrolysis of glycogen to glucose. Biomass Bioenergy 2015, 76, 61-68.

7. Ladera, R.M.; Fierro, J.L.G.; Ojeda, M.; Rojas, S. TiO2-supported heteropoly acids for low-temperature synthesis of dimethyl ether from methanol. J. Catal. 2014, 312, 195-203.

8. Santos, J.S.; Dias, J.A.; Dias, S.C.L.; de Macedo, J.L.; Garcia, F.A.C.; Almeida, L.S.; de Carvalho, E.N.C.B. Acidic characterization and activity of $\left(\mathrm{NH}_{4}\right)_{x} \mathrm{Cs}_{2.5-x} \mathrm{H}_{0.5} \mathrm{PW}_{12} \mathrm{O}_{40}$ catalysts in the esterification reaction of oleic acid with ethanol. Appl. Catal. A 2012, 443-444, 33-39.

9. Jing, F.L.; Benjamin, K.; Elisabeth, B.R.; Franck, D.; Sébastien, P. Structural Evolution under Reaction Conditions of Supported $\left(\mathrm{NH}_{4}\right)_{3} \mathrm{HPMo}_{11} \mathrm{VO}_{40}$ Catalysts for the Selective Oxidation of Isobutane. Catalysts 2015, 5, 460-477.

10. Li, Y.Y.; Huang, T.P.; Wu, Q.Y.; Xu, L. Synthesis and conductive performance of quaternary molybdotungstovanadophosphoric heteropoly acid with Keggin structure. Mater. Lett. 2015, 157, 109-111.

11. Zhou, L.L.; Wang, L.; Zhang, S.J.; Yan, R.Y.; Diao, Y.Y. Effect of vanadyl species in Keggin-type heteropoly catalysts in selective oxidation of methacrolein to methacrylic acid. J. Catal. 2015, 329, 431-440.

12. Rafiee, E.; Eavani, S. Controlled immobilization of Keggin-type heteropoly acids on the surface of silica encapsulated $\gamma-\mathrm{Fe}_{2} \mathrm{O}_{3}$ nanoparticles and investigation of catalytic activity in the oxidative esterification of arylaldehydes with methanol. J. Mol. Catal. A 2013, 373, 30-37.

13. Alharbi, W.; Brown, E.; Kozhevnikova, E.F.; Kozhevnikov, I.V. Dehydration of ethanol over heteropoly acid catalysts in the gas phase. J. Catal. 2014, 319, 174-181.

14. Augusto, L.P.M.; Maíra, S.C.; Kelly, A.S.R.; Elena, V.G. Heteropoly acid catalyzed cyclization of nerolidol and farnesol: Synthesis of $\alpha$-bisabolol. Appl. Catal. A 2015, 502, 271-275.

15. Chen, D.; Xue, Z.; Su, Z. A new catalyst of 12-molybdophosphoric acid for cationic polymerization of styrene: Activity and mechanism studies. J. Mol. Catal. A 2003, 203, 307-312.

16. Chen, D.; Xue, Z.; Su, Z. Dual role study of 12-molybdophosphoric acid on styrene polymerization. J. Mol. Catal. A 2004, 208, 91-95.

17. Rao, P.M.; Wolfson, A.; Kababya, S.; Vega, S.; Landau, M.V. Immobilization of molecular $\mathrm{H}_{3} \mathrm{PW}_{12} \mathrm{O}_{40}$ heteropolyacid catalyst in alumina-grafted silica-gel and mesostructured SBA-15 silica matrices. J. Catal. 2005, 232, 210-225.

18. Yang, L.; Qi, Y.; Yuan, X.; Shen, J.; Kim, J. Direct synthesis, characterization and catalytic application of SBA-15 containing heteropolyacid $\mathrm{H}_{3} \mathrm{PW}_{12} \mathrm{O}_{40}$. J. Mol. Catal. A 2005, 229, 199-205.

19. Dimitratos, N.; Pina, C.D.; Falletta, E.; Bianchi, C.L.; Santo, V.D.; Rossi, M. Effect of Au in $\mathrm{Cs}_{2.5} \mathrm{H}_{1.5} \mathrm{PVMo}{ }_{11} \mathrm{O}_{40}$ and $\mathrm{Cs} 2.5 \mathrm{H}_{1.5} \mathrm{PVMo}_{11} \mathrm{O}_{40} / \mathrm{Au} / \mathrm{TiO}_{2}$ catalysts in the gas phase oxidation of propylene. Catal. Today 2007, 122, 307-316. 
20. Audic, N.; Clavier, H.; Mauduit, M.; Guillemin, J.C. An Ionic Liquid-Supported Ruthenium Carbene Complex: A Robust and Recyclable Catalyst for Ring-Closing Olefin Metathesis in Ionic Liquids. J. Am. Chem. Soc. 2003, 125, 9248-9249.

21. Carmichael, J.A.; Haddleton, D.M.; Stefan, A.F.; Seddon, K.R. Copper(II) mediated living radical polymerization in an ionic liquid. Chem. Commun. 2000, 14, 1237-1238.

(C) 2015 by the authors; licensee MDPI, Basel, Switzerland. This article is an open access article distributed under the terms and conditions of the Creative Commons Attribution license (http://creativecommons.org/licenses/by/4.0/). 